\title{
"Vamos criar seu filho": os médicos puericultores e a pedagogia materna no século $\mathrm{XX}$ *
}

\section{"Let's raise your child": puericulture doctors and maternal pedagogy in the twentieth century}

\author{
Ana Paula Vosne Martins \\ Departamento de História / Universidade Federal do Paraná \\ Rua Heitor Baggio Vidal, 1746, casa 5 \\ 82820-120 Curitiba - PR Brasil \\ ana_martins@uol.com.br
}

\begin{abstract}
MARTINS, Ana Paula Vosne. "Vamos criar seu filho": os médicos puericultores e a pedagogia materna no século XX. História, Ciências, Saúde - Manguinhos, Rio de Janeiro, v.15, n.1, p.135-154, jan.-mar. 2008.

Analisa a produção da literatura médica de aconselhamento para as mães com o objetivo de ensiná-las a criar seus filhos. Tratando de assuntos como alimentação, vestuário, higiene e comportamento, os médicos puericultores acreditavam que somente o amor não era suficiente para uma boa formação e educação dos filhos. Como portadores da verdade científica e da técnica, os médicos procuraram ensinar as mães a seguirem os princípios da puericultura, contribuindo sobremaneira para a constituição da mãe-enfermeira, ideal preconizado pelos autores de três manuais publicados entre 1938 e 1963.
\end{abstract}

Palavras-chave: maternidade; aconselhamento médico; infância; puericultura.

MARTINS, Ana Paula Vosne. "Let's raise your child": puericulture doctors and maternal pedagogy in the twentieth century. História, Ciências, Saúde - Manguinhos, Rio de Janeiro, v.15, n.1, p.135-154, Jan.-Mar. 2008.

The article addresses the production of medical literature that offered advice on how mothers should raise their children. Doctors specializing in puericulture - educating mothers about topics like food, dress, hygiene, and behavior - believed that love alone was not enough to provide children with good training and education. As representatives of scientific truth and technique, these doctors tried to teach mothers to act according to the principles of puericulture, contributing primarily to the construction of the mother-nurse, an ideal endorsed by the authors of the three manuals published between 1938 and 1963 that are analyzed in this article.

Keywords: maternity; medical counseling; childhood; puericulture. 
Não basta que o amor materno tenha a força de um sentimento instintivo: é preciso iluminá-lo com os conhecimentos da puericultura para que todo o bem feito ao bebê seja um bem consciente e lúcido.

Franklin de Oliveira, O Cruzeiro, 10 out. 1953

$\mathrm{N}$ as últimas décadas do século XX e no começo do século XXI, um tema recorrente nos diferentes tipos de mídia é a educação dos filhos. Se compararmos com a época de nossas bisavós e avós, um primeiro aspecto a notar é a crescente insegurança dos pais em relação a como melhor agir com seus filhos, procurando nos especialistas respostas para as temíveis crises de choro, teimosias incontornáveis, exigências de consumo e as tais 'personalidades fortes' dos pequenos, alguns ainda de fraldas. "Que fazer?", perguntam pais e mães. Como agir sem comprometer o desenvolvimento psicológico, sem causar traumas e problemas para os filhos? Outra pergunta que as avós e bisavós nem imaginavam fazer: "Como ser mãe e ser pai?"

Em pesquisa com história oral entrevistei uma senhora com mais de oitenta anos de idade que foi parteira e atualmente é aposentada. Ao perguntar a ela sobre os cuidados que dispensou aos seus filhos e se havia contado com ajuda e conselhos de outras pessoas, ela respondeu que não havia nada de tão especial para ser aprendido no cuidado com os recém-nascidos, pois para ela, o cuidado com os bebês é algo muito simples. E estranhou que alguma mulher não soubesse cuidar deles.

Se prestarmos atenção no número de publicações especializadas disponíveis atualmente que abordam questões relacionadas aos cuidados com bebês, crianças pequenas e adolescentes, parece ter acontecido algo que contraria a opinião da experiente parteira, ou seja, cada vez mais homens e principalmente mulheres parecem não ter a menor idéia de como cuidar de seus filhos e criá-los. O desejo de ter filhos faz-se acompanhar de uma crescente ansiedade e de dúvidas sobre praticamente tudo, a começar pelo parto, passando pelo tipo de amamentação, isso sem falarmos das atitudes em relação ao comportamento dos bebês e do melhor método para educar as crianças e lidar com as transformações da adolescência.

Ao longo dos últimos quarenta anos, o mercado editorial de livros e revistas especializadas vem crescendo, talvez na mesma medida em que aumenta a insegurança dos pais em relação ao cuidado e à criação dos filhos. Uma consulta rápida nos títulos de livros, revistas e, mais recentemente, nos sítios da internet, mostra como esse assunto não cessa de arregimentar especialistas, editores e leitores. De um lado vemos uma polifonia de opiniões e de conselhos dos mais diversos especialistas como pediatras, psicólogos e pedagogos. De outro lado, a avidez silenciosa de leitores que admitem nada ou pouco saber sobre a criação dos filhos, admitindo que num mundo cada vez mais segmentado em competências específicas e técnicas, criar filhos também demanda conhecimento, método e técnicas complexas, pois crianças não são miniaturas de adultos; é o que aprendemos. A vida para os pais parece ter ficado, também, mais difícil e incerta do que foi para a minha experiente entrevistada.

O que este artigo pretende demonstrar é que uma das origens do quadro que estamos comentando foi a constituição, ainda no século XIX, da especialidade médica pediátrica e de seu projeto educativo e formativo, a puericultura, visando melhorar a saúde e as condições de vida 
das crianças por meio do aconselhamento e educação das mães, afinal elas eram consideradas, como ainda o são, as responsáveis pela criação dos filhos. A execução desse projeto exigiu, necessariamente, o estabelecimento de um meio de comunicação entre os especialistas e as mães que fosse eficaz e atingisse a maior audiência possível. As mulheres das classes privilegiadas e letradas foram as primeiras a receber as orientações e os conselhos médicos porque eram mais permeáveis às prédicas sobre a saúde física e moral dos filhos, tema caro às sensibilidades burguesas e às pretensões diferencialistas de classe e raça por meio do autocontrole e da disciplina.

No entanto, um grande número de mães das classes menos abastadas e populares continuava alheio aos conhecimentos da nova ciência da puericultura. Para suprir essa demanda os médicos passaram a escrever livros para as mães em linguagem mais simples, traduzindo para elas os conhecimentos especializados sobre a infância. Também passaram a responder as cartas que as mães escreviam para as seções de jornais e revistas, a fazer palestras e pequenos cursos de puericultura, além de utilizar o rádio, meio de comunicação de massas do século XX, ampliando consideravelmente a audiência de suas preleções.

Neste artigo analiso três livros de aconselhamento médico para as mães escritos por médicos pediatras brasileiros e publicados entre as décadas de 1930 e 1960. O primeiro, de 1938, foi escrito por Carlos Prado. Os outros dois, de Martinho da Rocha e de Rinaldo de Lamare, foram escritos na mesma época, mas para a elaboração deste artigo não tive acesso às primeiras edições. Meu objetivo aqui é mostrar como esses autores aderiram às teorias e aos princípios da pediatria e da puericultura, apresentando uma análise baseada na estrutura narrativa dos seus livros, nos temas selecionados e, principalmente, no tipo de diálogo que tencionavam estabelecer com suas leitoras, as mães. Recorrendo à historiografia que desde a década de 1970 vem se dedicando a estudar a produção dos saberes especializados sobre a família, a mulher e a criança, procurei comparar os três autores para salientar as idéias que compartilham e suas diferenças, tanto no que se refere às técnicas e métodos de criação, quanto no que se refere à relação entre médico e mãe.

Esses livros são exemplares do início do processo de consolidação da autoridade do especialista em crianças e da relação que ele estabelece com a mãe, uma relação desigual e assimétrica que expressa não só a diferença entre o leigo e o especialista, mas também a diferença de gênero. A construção do texto de aconselhamento médico parte de alguns lugares marcados pelo gênero, contrapondo de um lado o médico, seu conhecimento e sua autoridade, e de outro a mãe, moldada pela natureza, mas sem conteúdo, ou seja, sem conhecimento, esperando pela condução do médico. Como pai severo, o professor preocupado com suas discípulas ou como o médico amigo, os especialistas construíram não só o saber puericultor, mas estabeleceram as bases para a educação das mães ao afirmar que elas nada ou pouco sabiam a respeito dos seus filhos e de como criá-los, desqualificando qualquer saber que não fosse o médico.

Os especialistas criaram, assim, as condições para a legitimação de sua autoridade ao mesmo tempo em que semearam a desconfiança sobre as práticas e os saberes maternos transmitidos pelas mães, sogras, vizinhas e amigas, consideradas perniciosas, ignorantes e nocivas para a saúde das crianças. Para as mães só restava a solidão de suas inquietações e as responsabilidades crescentes de uma maternidade que não devia ser compartilhada com mais ninguém a não ser o médico, o único capaz de conduzir a mulher-mãe, de educá-la e corrigi-la, a fim de não se desviar dos ensinamentos produzidos pelo conhecimento especializado. 


\section{Especialistas em crianças}

A preocupação com as crianças e a transformação desta fase da vida em algo especial por si mesma, digna de respeito e de cuidados específicos, é algo muito recente nas sociedades ocidentais. Pelo menos desde o século XVII autores como John Locke defendiam métodos educativos mais centrados no exemplo moral dos pais e no ensino adequado para a idade das crianças, rejeitando a severidade e os excessos de castigos físicos. A partir do século XVIII pensadores como Rousseau, Madame d'Épinay e Pestalozzi chamaram a atenção para a especificidade e as necessidades da infância, denunciando práticas e métodos educativos inadequados para a compreensão das crianças e para o seu desenvolvimento físico, moral e intelectual. Esses autores desenham uma nova imagem da criança semelhante à semente de uma árvore, promessa de futuro, contanto que bem orientada e conduzida. As publicações desses autores e o método educativo proposto por eles encontraram guarida ainda no século XVIII, mas foi no século seguinte que suas idéias foram aplicadas pelas escolas e principalmente pelos pais, que começaram a ver suas crianças de uma forma mais afetiva.

A criança passou a ser cada vez mais valorizada entre as classes mais abastadas e urbanas, deixando de ser vista como mão-de-obra ou depositária e transmissora do sangue e do nome da família. Documentos da vida íntima, como cartas e diários produzidos por mulheres e também por homens do final do século XVIII e inícios do século XIX, revelam uma nova sensibilidade para com os filhos, cada vez mais percebidos pelas classes abastadas como seres especiais, merecedores de amor e de cuidados redobrados. A perda de um filho passou a ser algo muito temido e lamentado, irreparável não só para os pais, mas para a sociedade.

Essa nova sensibilidade burguesa está representada não só nos documentos pessoais, mas também na literatura do século XIX e nos textos médicos. Esses já compartilhavam de algumas das idéias inovadoras sobre a educação das crianças desde o século XVIII, mas ao longo do século seguinte os médicos foram bastante atuantes em favor de uma mudança não só nos métodos educativos, mas também na forma de se cuidar dos filhos para que esses gozassem de saúde e, como as sementes, germinassem e crescessem. O hábito de chamar o médico para atender nas casas das famílias mais abastadas foi se tornando comum a partir do final do século XVIII na Europa, assim como a entrada dos médicos na cena do parto. A aproximação entre médicos e mulheres, a princípio bastante restrita às classes altas, possibilitou maior conhecimento sobre a gravidez, o parto, os primeiros cuidados com o recém-nascido e as doenças infantis, ampliando a confiança das mulheres nos médicos não só para atendê-las, mas também para com seus filhos pequenos.

Outra explicação para a visibilidade da criança no século XIX é a crescente onda de humanitarismo e a formulação da crítica social pelo movimento filantrópico e pelos movimentos políticos de cunho socialista, mais atuantes na segunda metade do século. As promessas de progresso, riqueza e bem-estar do capitalismo não se concretizaram, como qualquer morador mais atento das grandes cidades européias e dos Estados Unidos podia comprovar. A riqueza não era para todos, e aqueles que trabalhavam eram os mais expropriados e infelizes, como podemos ver na literatura inglesa e francesa da época. Relatórios oficiais, por sua vez, mostravam os números frios da miséria e seus efeitos nos corpos dos trabalhadores, especialmente daqueles pequenos trabalhadores que cumpriam jornadas de 14 horas ou até mais de trabalho desde os cinco anos de idade. 
Crescia, assim, uma reação ao liberalismo econômico na Europa e nos Estados Unidos, por parte da filantropia de motivação religiosa, como também da política socialista e anarquista. Os médicos contribuíram ativamente para essa reação ao fornecer estatísticas pessoais ou oficiais lançando o alerta sobre a mortalidade infantil, que na primeira metade do século XIX atingia crianças de todas as classes sociais, mas que era mais forte nas classes populares urbanas. A partir da década de 1840, o envolvimento dos médicos é mais notável, especialmente na França e na Inglaterra, mudando paulatinamente o tom de seus discursos ao realçar os efeitos políticos da mortalidade infantil. A partir da segunda metade do século XIX, o tom de alerta se eleva e fica mais dramático, tendo em vista a queda da natalidade entre as classes altas e a discussão sobre a qualidade física dos soldados franceses suscitada pela derrota na guerra contra a Prússia, no início da década de 1870. Criar filhos, diziam os médicos a partir de então, não podia ser algo deixado à boa vontade dos pais. Os médicos deviam servir de guia onde fosse possível atuar - ou seja, entre as classes mais abastadas e permeáveis aos seus conselhos -, e o Estado, apoiado pela obra filantrópica, devia se responsabilizar pela salvação das crianças entre as classes populares, sementeiras de soldados e trabalhadores.

O envolvimento dos médicos com a crítica social e a proteção das crianças pobres não os afastou dos misteres da profissão. A partir da década de 1860, a pediatria começa a dar os seus primeiros passos como uma especialidade médica, acompanhando a evolução de outras especialidades como a obstetrícia, a ginecologia e a psiquiatria, articulando a clínica ao ensino e à investigação científica dos fenômenos fisiopatológicos relacionados à criança. Surgem as primeiras publicações sobre as doenças infantis, em particular aquelas relacionadas à alimentação e à amamentação mercenária. Na França, a pediatria se desenvolveu notadamente nas últimas décadas do século XIX, tanto no aspecto clínico e cirúrgico, quanto no aspecto preventivo, lançando as bases da "ciência e arte que tratam da procriação e criação da espécie humana", a puericultura (Costa, 1955, p.11). Médicos como Pinard, Budin, Dufour e Variot não só se dedicaram à clínica médica pediátrica, mas também à profilaxia, defendendo a necessidade de medidas preventivas de caráter educativo, essencialmente, e voltadas para a educação das mães.

Com a definição dos contornos programáticos da puericultura os primeiros resultados dessa visibilidade e importância dada à saúde da criança se fazem notar já no alvorecer do século XX. As primeiras reuniões científicas de pediatria e puericultura começaram a acontecer na primeira década do século XX, como o Congresso sobre os Problemas da Alimentação Infantil, realizado em Paris, em 1905; o Congresso sobre a Proteção da Primeira Infância, em 1907, na cidade de Bruxelas; e o Congresso Nacional sobre a Criança, em 1909, em Washington. Durante a década de 1910 ocorreram vários congressos similares tanto na Europa quanto na América Latina, como o Primeiro Congresso Pan-americano da Criança, realizado em Buenos Aires, no ano de $1916 .{ }^{1}$

O estabelecimento de um fórum médico internacional sobre a infância contribuiu significativamente para a inserção do tema da proteção das crianças nas agendas políticas nacionais, mas também do próprio movimento de mulheres. Na mesma época em que os congressos médicos aconteciam, reuniões internacionais e nacionais de mulheres feministas e não-feministas também debatiam problemas relacionados à questão social que atingiam as condições de vida das mulheres trabalhadoras e de seus filhos. O feminismo do começo do 
século XX tinha como uma de suas causas mais importantes e mobilizadoras a proteção à maternidade, conseguindo, assim, apoio de outras organizações femininas de caráter mais conservador e de homens sensibilizados pela mesma causa, como é o caso dos médicos (Bock, Thane, 1996).

O envolvimento de todos esses agentes sociais com a questão da infância teve um impacto considerável nas políticas públicas dos países europeus e americanos no começo do século, como se pode perceber pela legislação social. Leis regulamentando o trabalho de mulheres e de menores nas fábricas e em lugares insalubres, a regulamentação da amamentação mercenária, a concessão de abonos-maternidade, a obrigatoriedade de creches em estabelecimentos com certo número de mulheres trabalhadoras e a construção de lactários, tanto pela iniciativa privada quanto pelos poderes públicos, são algumas das medidas tomadas desde o final do século XIX em favor da infância e da maternidade.

As questões da criança passam a transcender o humanitarismo e a própria clínica médica. O tom humanitário dos discursos começa a se atenuar frente às argumentações de natureza política e racial, especialmente a partir do final do século XIX. A família e a criança passam a ser vistos como agentes políticos, promessas do futuro da nação e da raça. Desta forma, os médicos puericultores e higienistas propõem um tripé de medidas protetoras articuladas, a começar pelo papel dos especialistas, responsáveis pela produção do conhecimento sobre a infância e pela orientação das políticas de saúde e bem-estar. O Estado é o outro agente importante dessa configuração, responsável pela formulação de uma legislação protetora da criança, da mulher e da família, bem como pela implementação das políticas públicas. Por fim, o agente considerado mais importante e vital para que essas medidas protetoras tivessem eficácia é a mãe. Consideradas as responsáveis diretas pelo bem e pelo mal das crianças, as mulheres sofreram um processo de culpabilização pelas doenças e pela morte dos filhos, pois segundo os médicos, algumas eram teimosas, ignorantes e apegadas às práticas da medicina popular, fonte de abusos e de erros, segundo a interpretação da medicina clínica. Cabia aos médicos, apoiados pelo Estado e pela iniciativa privada, orientar as mães, conduzi-las pelo reto caminho da puericultura, disciplinando-as e fiscalizando as suas práticas.

$\mathrm{Na}$ verdade os médicos atuaram nas três pontas do tripé. Primeiro como especialistas, atuando na clínica, organizando-se e divulgando seus conhecimentos. Segundo, atuando junto às instâncias políticas, seja como funcionários públicos, seja como legisladores. Por fim, encarregaram-se da tarefa que lhes cabia mais diretamente, a educação das mães, por meio das consultas médicas nos hospitais infantis, dispensários, Gotas de Leite e lactários e, principalmente, por meio dos livros de puericultura, das cartas publicadas em jornais e revistas, palestras educativas, dos programas de rádio e, posteriormente, da televisão. Começaram, assim, a lenta e gradual tarefa de educar as mães, procurando transformá-las em suas aliadas na luta contra os males que ameaçavam a vida das crianças, mas também na disseminação dos saberes médicos, uma tarefa de aculturação que não foi fácil, especialmente em países como o Brasil, onde a inserção dos médicos foi, por muito tempo, restrita aos centros urbanos maiores e, mesmo nesses locais, essa inserção enfrentou resistências por parte das mães, no que diz respeito às práticas e aos saberes sobre a criação dos filhos.

A divulgação do saber puericultor entre as mães parecia, portanto, ser tarefa das mais urgentes. Os conselhos dados nos consultórios ou por ocasião das visitas médicas nos domicílios 
não eram suficientes, nem extensivos como pensavam os médicos. A tarefa era, antes de tudo, educativa, lançando mão de métodos modernos de comunicação que pudessem atingir o maior número possível de mães. Iniciava-se, portanto, a partir das primeiras décadas do século $\mathrm{XX}$, a pedagogia materna, a princípio conduzida pelos médicos e, posteriormente pelas escolas, ensinando noções básicas de higiene infantil e divulgando informações sobre as doenças infantis e primeiros socorros. Mas a lição mais importante deste processo pedagógico era estabelecer as competências e as responsabilidades: aos médicos cabia o papel de mestre, enquanto às mães cabia a responsabilidade de seguir os conselhos de seus mestres, sem tergiversações, a fim de assumir de maneira consciente e bem informada a mais importante responsabilidade que lhes cabia: saber ser mãe.

\section{A pedagogia materna}

A produção do saber médico especializado sobre crianças fez-se acompanhar da literatura de aconselhamento para as mães pelo menos desde o final do século XIX nos Estados Unidos e em alguns países europeus. Os Estados Unidos foram pioneiros nas publicações destinadas à educação das mães, enquanto na Europa e na América Latina essas publicações começaram a aparecer por volta das décadas de 1920 e 1930. Esse pioneirismo estadunidense se deve, em grande parte, a um movimento reformista de caráter conservador cujas origens estão no início do século XIX com a industrialização e a expansão da economia de mercado. Mudanças sociais impulsionadas pela urbanização e industrialização tiveram um impacto considerável sobre as vidas das mulheres norte-americanas, tanto aquelas das classes médias, quanto as das classes trabalhadoras. Para as primeiras, as tarefas domésticas que antes eram muito diversificadas e ocupavam todo o tempo - cozinha, costura, lavanderia, limpeza - começaram a ser facilitadas ou até mesmo substituídas pela indústria e o comércio urbano. Segundo Ehrenreich e English, "cada vez com menos tarefas, parecia que logo a mulher [de classe média] não teria nada para fazer em casa. Educadores, escritores populares e cientistas sociais conhecidos se preocupavam com o crescente vazio dos lares" (2003, p.159). Certamente para as mulheres das classes trabalhadoras esse vazio não se configurava, pois além de continuar a fazer o trabalho doméstico com as mesmas técnicas pré-industriais, trabalhavam fora do lar para manter suas famílias.

No entanto esse foi o ponto de partida, nos Estados Unidos, para uma série de pronunciamentos doutos a respeito do lar, da economia doméstica e do papel das mulheres como donas de casa e mães. Na virada do século XIX para o XX homens e mulheres cultos passaram a defender uma abordagem científica do lar e da maternidade como forma de resolver os impasses e as ansiedades sobre a Questão da Mulher. Se uma concepção liberal e científica da sociedade não podia mais admitir que as mulheres fossem consideradas inferiores aos homens, fazia-se necessário educá-las, não para estimular a competição entre os sexos, mas para que cada um pudesse desempenhar seus papéis de forma mais adequada aos tempos modernos.

Além da ciência doméstica, que teve nos Estados Unidos um número bastante significativo de defensores, contando com escolas especializadas no assunto, bem como publicações e uma organização profissional, no final do século XIX a medicina contribuiu para esse processo de construção do lar científico ao 'descobrir a criança'. ${ }^{2}$ Se a criança era um ser com necessidades 
e especificidades próprias, importante por si mesma, o elo entre o presente e o futuro, os médicos passaram a escrever sobre o assunto, partindo do princípio de que não havia um modo natural de criar filhos, ou seja, as mães, por mais amorosas e bem intencionadas, cometiam muitos erros e deviam ser guiadas pela racionalidade científica da medicina e dos especialistas. É nesse contexto que foi publicado o livro que guiou a criação dos filhos nos Estados Unidos, pelo menos até a época da Segunda Guerra Mundial, e que exerceu grande influência no pensamento pediátrico da época. Trata-se do livro The care and the feeding of infants, de Emmett Holt, publicado em 1896. Holt é considerado o primeiro pediatra norte-americano, e seus conhecimentos e conselhos sobre a criação de filhos foram divulgados pelo governo por meio de boletins do Children's Bureau, entre 1914 e 1921 (Hulbert, 2004).

É importante destacar o livro de Holt não só porque foi o primeiro manual científico escrito por um especialista em crianças direcionado para as mães, mas também pelo método preconizado, baseado na regularidade e na dieta alimentar, fazendo escola, tanto na Europa, quanto nos países latino-americanos. Seu método se baseava numa educação centrada nos pais, mais especialmente na mãe, enfatizando a disciplina e o controle das emoções ao lidar com a criança. Escrito em linguagem acessível, o livro de Holt primava pelo didatismo e pelos detalhes, ensinando as mães a agirem como verdadeiras cientistas nos seus lares-laboratórios, medindo, calculando, pesando, anotando dúvidas para serem dirimidas pelo médico, enfim, desdobrando cada ação em várias etapas, munidas com balança, termômetro, recipientes graduados, colheres de medidas, tabelas de alimentos e de crescimento infantil, aprendendo não só a agir com método, mas a pensar como um cientista ou uma enfermeira, "o que significava agir com calma e nunca perder a paciência" (Hulbert, 2004, p.69).

Na Inglaterra outro livro fazia grande sucesso. Em 1913 foi publicada a edição inglesa do livro The feeding and care of baby, de Frederic Truby King, médico neozelandês que se dedicou à assistência materno-infantil, ardoroso defensor da amamentação materna. Suas idéias não eram diferentes das de Holt, particularmente no que diz respeito ao método científico de criar filhos, pois salientava também a regularidade e a disciplina, bem como o controle das emoções, desaconselhando que as mães embalassem os bebês e propondo que evitassem os contatos físicos, como beijos e carícias (Forna, 1999).

As idéias e o método divulgados por Holt e Truby King tiveram grande aceitação, tanto pelos especialistas quanto pelas mães. Ann Hulbert (2004, p.199) comenta que o órgão público responsável pelas políticas de saúde materno-infantil nos Estados Unidos, o Children's Bureau, recebeu centenas de milhares de cartas escritas pelas mães na época em que publicou o boletim com os conselhos de Holt, evidência de que havia uma audiência ávida por informações. Essa vontade de saber certamente foi estimulada pelos próprios médicos, por causa da clientela mais abonada, mas também pelo trabalho social dos funcionários públicos, como as enfermeiras, as assistentes sociais, as visitadoras sociais e as parteiras que freqüentavam cursos de treinamento. Lentamente o trabalho articulado entre médicos, filantropos e funcionários públicos criou entre as mães da classe média uma demanda por conhecimentos autorizados, científicos, sobre a melhor e mais adequada forma de criar filhos. Registros em diários, cartas para os jornais e revistas, como também as memórias das mães são reveladores da eficácia da pedagogia materna iniciada nos países de língua inglesa no início do século XX, como demonstra Forna (1999). Entretanto, isso não significa que as mães seguiam obedientemente as lições dos 
médicos, pois, provavelmente, selecionavam o que liam e adotavam algumas orientações de caráter prático, descartando aquelas mais difíceis ou que se mostrassem inadequadas aos seus valores e sentimentos, como a questão do contato físico com os bebês.

Na França, outro país cujo pensamento médico pediátrico tornou-se referência internacional, a pedagogia materna iniciou um pouco mais tarde, na década de 1920. Embora os médicos franceses estivessem entre os primeiros a definir e praticar a puericultura, nenhum livro teve na língua francesa o mesmo impacto que os de Holt e King tiveram na língua inglesa. Os puericultores franceses também acreditavam que as mães deviam ser educadas pelos especialistas, mas até a década de 1920 foram poucos os manuais de puericultura publicados para leigos. A imprensa feminina e feminista dedicava alguns artigos à questão desde o final do século XIX, divulgando o saber puericultor e conselhos sobre a criação dos filhos. Entretanto, foi somente no período entre guerras que os médicos franceses começaram a publicar manuais de puericultura, dando início à pedagogia materna. Segundo Françoise Thebaud as idéias e o método preconizado pela puericultura francesa não diferem de seus colegas de língua inglesa, divulgando prescrições detalhadas sobre a gravidez, a higiene do bebê, a alimentação regulada, a disciplina e o controle das emoções com a limitação dos contatos físicos entre a mãe e a criança (Thehaud, 1986, p.129-130).

De uma forma geral, a pedagogia materna que começou a ser formulada pelo pensamento médico puericultor, tanto na Europa quanto nos Estados Unidos, partia de uma concepção marcadamente autoritária e assimétrica das relações entre médicos-mestres e mães-discípulas. Estabelecendo uma clivagem entre o saber médico e o saber leigo das mães, os médicos desqualificaram qualquer prática ou experiência que não tivesse fundamento científico e profissional. As mães são vistas com desconfiança e culpabilizadas pela mortalidade infantil, mas também são merecedoras da atenção e dos cuidados médicos. Como as crianças, as mães precisam ser educadas e os médicos atribuem a si essa tarefa por meio de um conjunto de práticas e de uma metodologia própria cujo objetivo é, em síntese, a normalização da maternidade.

No Brasil, a pedagogia materna se inicia com o projeto colonizador, como bem demonstrou Mary Del Priore ao sublinhar a importância do modelo da mãe virtuosa e católica para o controle social das populações segundo os interesses do Estado português e da Igreja católica reformada (Del Priore, 1993). Autores portugueses dos séculos XVII e XVIII publicaram livros sobre a criação dos filhos procurando direcionar os pais para o melhor método de educação. Herdeiros de uma literatura civilizacional nos moldes do famoso livro de Erasmo, A civilidade pueril, publicado em 1530, nota-se, nesses livros, a inclusão e mesmo a sobreposição de outros saberes e interesses que visavam o governo das populações; daí a ênfase nos cuidados com o corpo dos infantes, com a alimentação, os exercícios físicos e não só com os comportamentos e a educação moral e religiosa. ${ }^{3}$

No entanto, o alcance desses livros era muito limitado, pois se o número de mães capazes de ler em Portugal era bastante restrito, na América portuguesa esse número era ainda menor. Livros como esses eram lidos por poucas mulheres e certamente por um número maior de fidalgos mais ilustrados que desejavam orientar-se melhor nos assuntos pedagógicos para bem criar seus filhos.

A pedagogia materna recebe um impulso significativo no Brasil com o projeto médico higienista que passou a ser formulado no século XIX com a institucionalização do conhecimento 
médico nas faculdades de medicina. Jurandir Freire Costa mostrou como os médicos brasileiros rejeitaram o sistema familiar herdado dos tempos coloniais centrado no pai e nos seus interesses (Costa, 1979). Para salvar as crianças, aperfeiçoá-las para que crescessem saudáveis e úteis para essa grande família que é a nação, todo o sistema familiar deveria ser reformado, do casamento à organização da família; do sexo conjugal à criação dos filhos. É com o novo entendimento da necessidade de se organizar e controlar as famílias que a medicina construiu a mãe higiênica, essa 'amante dos filhos e aliada dos médicos', de acordo com Freire, a quem era preciso também orientar, convencer, admoestar e, se necessário, coagir para que bem desempenhasse o seu novo papel de boa e dedicada mãe.

A partir das décadas de 1840 e 1850 médicos brasileiros começaram a publicar livros sobre a criação de filhos orientados pelos princípios higienistas nos quais se reforça cada vez mais a importância da mãe como educadora e responsável pelo bem-estar das crianças. Algumas dessas publicações são: Guia médico das mães de família (1843), o jornal quinzenal A Mãe de Família (1880-1881), de Carlos Antônio de Paula Costa, e $A$ arte de formar homens de bem (1880), de Jaguaribe Filho (Aguiar, Martins, 1996; Martins, 2004).

É certo que se levarmos em consideração a existência das primeiras maternidades construídas no século XIX, dos consultórios populares mantidos pela filantropia e artigos publicados na imprensa, desde fins do século XIX e início do século XX, os conselhos sobre cuidados prénatais e de higiene infantil vinham sendo divulgados para um público maior. Contudo, essas primeiras iniciativas pedagógicas não eram voltadas exclusivamente para as mães, pois antes de tudo era importante convencer os outros médicos, as enfermeiras, as mulheres que atuavam na filantropia e as autoridades. Os dados estatísticos que Moncorvo Filho apresentava sobre a mortalidade infantil no Rio de Janeiro não visavam primordialmente persuadir as mães, mas seus próprios colegas de profissão e principalmente as autoridades. Os médicos pediatras alertavam que a questão da criança não era um problema só de saúde, mas tinha desdobramentos sociais e políticos e, em longo prazo, raciais. Portanto, no meio médico e filantrópico brasileiro das duas primeiras décadas do século XX não eram apenas as mães que tinham de ser convencidas a mudar suas práticas de cuidar dos filhos. Os profissionais da medicina e as autoridades também tinham de ser convencidos da urgência da questão da criança e se converter, cada um na sua esfera de ação, às orientações da puericultura.

A partir da década de 1920 esse trabalho de convencimento dos profissionais e das mulheres ligadas à filantropia parecia estar produzindo seus frutos. O ensino da pediatria nas Faculdades de Medicina estava regulamentado desde 1882, mas não havia no Brasil uma associação médica pediátrica. Em 1910, Fernandes Figueira, um dos nomes mais destacados da pediatria brasileira, fundou a Sociedade Brasileira de Pediatria, filial da Sociedade Internacional de Pediatria, criando assim um importante espaço de debate e produção do pensamento científico sobre a criança no país (Seta, 1997). É na década de 1920 que se realiza no Brasil o Primeiro Congresso Brasileiro de Proteção à Infância, entre 27 de agosto e 5 de setembro de 1922, junto ao Terceiro Congresso Pan-americano da Criança. Esse tipo de reunião nacional e internacional contribuiu sobremaneira para o fortalecimento da especialidade pediátrica no país, e é possível notar pelo número de comunicações e publicações relacionadas ao evento como o trabalho de convencimento dos médicos para os assuntos relativos à puericultura estava amealhando adeptos e defensores (Primeiro Congresso..., 1925). 
No que diz respeito às mulheres ligadas às instituições filantrópicas, desde o final do século XIX elas se organizaram para amenizar as condições de existência das pessoas muito pobres, em especial órfãos, idosos e doentes, geralmente como uma extensão de seu papel de mães e expressão do catolicismo leigo. Quando os médicos envolvidos com a questão da infância procuraram apoio para a construção de maternidades e outras instituições assistenciais para mães e crianças, contaram imediatamente com o apoio de associações femininas de proteção à maternidade e à infância. Representantes das classes média e alta, essas mulheres - nem todas movidas pela religião, é importante destacar - apoiaram os médicos e contribuíram decisivamente para a divulgação do saber puericultor, além de desempenharem importante papel na organização material das instituições, arrecadando fundos e contribuindo de diversas maneiras para a sua continuidade, antecipando, de certa forma, algumas das políticas públicas que o Estado viria a implementar mais tarde.

As autoridades brasileiras, sempre tão criticadas pelos médicos pela negligência em relação à infância e à maternidade, também foram convencidas da necessidade de políticas públicas voltadas para a questão da infância, mesmo que de forma ainda restrita. Em 1923 o decreto 16.300, que regulamentava o Departamento Nacional de Saúde Pública, atribuía à Inspetoria de Higiene Infantil a responsabilidade pela formulação das políticas de saúde materno-infantil no país. Embora ainda muito restritas, tanto no aspecto da extensão dos serviços quanto na abrangência territorial, a Inspetoria fiscalizava as maternidades na cidade do Rio de Janeiro e prestava atendimento médico nos postos ou ambulatórios de pré-natal, mantendo também alguns lactários no Distrito Federal e distribuindo leite esterilizado para as mães pobres que não podiam amamentar.

Dessa forma, percebe-se que o trabalho de convencimento médico em favor da maternidade e da infância no Brasil, iniciado ainda no século XIX, havia conquistado tanto os profissionais da medicina quanto a filantropia e as autoridades políticas no começo do século XX. Mas os médicos puericultores sabiam que isso não era suficiente. Faltavam as personagens mais importantes desse enredo da proteção e salvação das crianças: as mães.

É para elas, portanto, que os médicos escrevem, seja por meio das revistas femininas, seja pelas respostas a cartas de leitoras de jornais e revistas, ou ainda, por meio de livros produzidos exclusivamente para as mães, levando em conta o vocabulário, a estrutura em capítulos curtos, o estilo direto e objetivo e o uso de ilustrações e fotografias. Diferentemente dos livros publicados no século XIX, os livros escritos para a educação das mães foram estruturados como manuais. Ensinavam de forma simplificada os conhecimentos atualizados da puericultura e da pediatria, mas seu objetivo principal era ensinar as práticas relacionadas ao cuidado cotidiano das crianças, transformando ações simples como o banho, a troca de fraldas e a preparação do mingau ou 'sopinha' em tarefas complexas, desdobradas em múltiplos movimentos e informações. Esses manuais não só ensinavam a cuidar de bebês e crianças pequenas, mas estabeleciam uma dicotomia entre o autor e a leitora, perceptível não só pelo tom imperativo e pela voz ativa do médico-autor, mas pela construção discursiva da mãe leitora, passiva e paciente, aluna ideal para a recepção dos saberes especializados e autorizados dos médicos puericultores.

Passo agora a analisar os manuais e livros de puericultura para as mães, escritos por médicos brasileiros envolvidos com a questão da criança entre as décadas de 1930 e 1940. Carlos Prado, José Martinho da Rocha e Rinaldo de Lamare foram médicos pediatras e puericultores 
profundamente envolvidos com o debate sobre a infância no Brasil. Presidiram a Sociedade Brasileira de Pediatria e seus livros venderam muito, especialmente o livro de Rinaldo de Lamare, médico que atua também no Departamento Nacional da Criança (Prado, 1938; Rocha, s.d.; De Lamare, 1963). Seu livro ainda é lido pelas mães e se encontra na $41^{a}$ edição. Quanto à periodização, foi a partir dos anos 30 e particularmente após 1941 que se formulou uma política de saúde e assistência materno-infantil centralizada e coordenada pelo governo federal. Isso ocorreu na mesma época em que se observa no Brasil o processo de transição do parto doméstico para o parto hospitalar, como conseqüência tanto das políticas públicas, quanto da pedagogia materna.

Carlos Prado foi médico pediatra em São Paulo, e o livro Vamos criar seu filho, publicado em 1938, é resultado, segundo explica o autor, de seu trabalho na imprensa periódica desde 1925, respondendo cartas que eram enviadas para a seção de higiene infantil do Diário Nacional e a seção "Palavras às mães" do Diário de S. Paulo. Apresenta-se como um soldado da pediatria e da puericultura na luta contra os erros, os abusos e a ignorância que grassavam na medicina popular: "eu enfrentei galhardamente a fúria de todos os elementos hostis e com tato e finura e às vezes também com voz forte e mão pesada, fui esclarecendo as dúvidas, profligando as heresias, combatendo os erros e abusos de que está tão cheia, desgraçadamente, em nosso meio, a medicina popular" (Prado, 1938, p.9).

O livro é escrito na forma de crônicas curtas, todas inspiradas em algum caso narrado pelas cartas. Seu estilo é simples, direto, usa expressões populares e, muitas vezes, recria diálogos com personagens para expor os casos e explicar as situações e os modos de proceder. Desde o início explica que o grande inimigo a ser derrotado é a mortalidade infantil, "ponto alto e vergonhoso para a nossa vaidade de povo civilizado; um atraso" (Prado, 1938, p.15). Como pensavam seus contemporâneos, a causa da mortalidade infantil era a ignorância dos princípios da puericultura por parte das mães e das pessoas que as aconselhavam, como parteiras leigas, curandeiras, vizinhas e avós, para quem Prado não economiza palavras duras e seu opróbrio.

Seu livro é, sem dúvida, um manual para as mães, mas a narrativa se assemelha a um severo catecismo, no qual antes de informar sobre técnicas, práticas da puericultura e doenças infantis, estabelece os princípios da autoridade médica ao mesmo tempo em que desqualifica qualquer outro conhecimento ou prática popular de cuidados infantis. Assim sendo, sua narrativa alterna entre uma ironia zombeteira quando se refere à medicina popular e em particular às pessoas que a praticam, e uma atitude de severidade extrema com as mães, sem permitir nenhuma negociação ou aproximação mais amigável ou paternal. Desde o início, Prado deixa claro quem tem a autoridade para condenar o que era considerado errado e ordenar os procedimentos corretos à luz do saber puericultor. Nesse sentido seu livro não era exatamente um manual de aconselhamento, mas um catecismo com seu rol de proibições e ordenações.

O título do livro não deixa margens para dúvidas, pois se a mortalidade infantil era tão elevada no Brasil isso significava, segundo Prado, que as mães não estavam criando bem os seus filhos, portanto, cabia aos médicos aconselhá-las, estabelecendo as diferenças entre certo e errado, bom e mau, adequado e inadequado. A catequese científica, portanto, começa ao se estabelecer o médico como alguém que conhece a verdade, não da salvação das almas, mas da vida das crianças. As outras pessoas que aconselhavam as mães são, na narrativa de Prado, como hereges, pois propagavam erros, desviando as mães e corrompendo a saúde das crianças: 
"observar direito a criança e cumprir à risca as ordens do doutor, eis o papel da mamãe na conjugação comum de esforços para restituir a saúde do bebê" (Prado, 1938, p.23).

Prado apresenta as criaturas maléficas que cercavam as mães com seus saberes e práticas condenáveis pelo saber especializado e científico. São a 'vizinha Carmela', 'a sábia', 'Nhá Barbina' e as avós que "criaram seus filhos com leite de cabra, leite condensado, calomelanos, chá de poejo, jasmim de cachorro, mistura das três Marias, quarto fechado, escalda-pés e dentes de alho" (Prado, 1938, p.18). Para assustar suas leitoras, Prado explica que uma criação baseada nesse "faro científico" só poderia resultar em tipos com algum defeito, como em "microcéfalo, idiota, asmático, corcunda, dispéptico, reumático, banguela, a mocinha escanifrada, prognata e que sofre de enxaquecas" (Prado, 1938, p.19). Mas as críticas não foram só para as 'sabichonas'. Segundo Prado, as mães não auxiliavam os médicos ao darem ouvidos às 'sabichonas'. Além disso, falavam muito e traziam informações sem valor para o médico e, o que era mais condenável, não seguiam as recomendações médicas ou então faziam tudo errado, por serem teimosas ou ignorantes.

Contudo, as crianças não estavam mais abandonadas às mãos das mães teimosas e das 'sabichonas', visto que a 'pediatria benfazeja' estava a postos e contava em seu arsenal com conhecimentos científicos que podiam salvar a vida das crianças, garantindo, para o futuro, "uma legião eutrófica de homens sadios e úteis para a família e a sociedade" (Prado, 1938, p.21). Bastava que as mães se convencessem de seu papel e seguissem as ordens médicas como as que Prado desfiava em seu livro.

Essas ordens seguiam um método muito simples e baseado em dois princípios irrevogáveis: disciplina e terapia nutricional. Na realidade, o princípio fundamental era a disciplina, pois no que se referia à alimentação infantil, o rigor com os horários, a qualidade dos alimentos e as medidas seguiam estritamente o princípio da disciplina empregado em outros aspectos dos cuidados infantis. Nesse sentido o livro de Prado adotava o mesmo método preconizado por seus colegas estrangeiros, em particular o método rigoroso e severo dos pediatras da escola anglo-saxã de Holt e Truby King e dos pediatras franceses.

A disciplina é acentuada pelo autor desde o nascimento da criança. Prado temia os efeitos de uma criação sem disciplina, tanto para a saúde física da criança, quanto para a saúde mental. Ensinava às mães que o ideal para a criança recém-nascida é ficar em local silencioso, sem receber visitas, e que deveriam evitar pegá-la no colo e mesmo beijá-la. Prado era totalmente contrário às carícias, especialmente os beijos, mas reservou algumas de suas admoestações mais severas às mães que pegavam os bebês no colo para cessar o choro. Pior que pegar no colo quando a criança chorava era o embalo, tanto nos braços, quanto no berço móvel ou na rede. Sem recorrer às explicações psicológicas ou psicanalíticas, Prado recusava as carícias porque acreditava serem elas excitantes, podendo transmitir doenças. Já a recusa ao colo quando a criança chorava era um ensinamento importante, segundo o médico, porque ao ceder ao choro a mãe estaria criando um neuropata, um verdadeiro tirano do lar. Prado explicava às mães que os bebês choravam sem motivo na maior parte das vezes, pois "sentem um prazer diabólico, um prazer mussolínico em dominar, com um simples berro, com um simples Dó de peito, aquela legião apalermada de parentes, amigos e vizinhos" (Prado, 1938, p.52). Desde muito pequena a criança devia aprender com sua mãe quem estava no controle, quem dominava, e o objetivo do livro era ensinar as mães como lidar com as vontades da criança, 
municiando-as com o conhecimento médico para que elas agissem sem receio de errar, não dando ouvidos para os leigos que se rendiam ao "Dó de peito" dos bebês pegando-os no colo e embalando-os ao som das cantigas tão desprezadas por Prado.

Na sua luta contra a intromissão dos leigos, em especial das leigas, na criação dos filhos, Prado reservou algumas passagens do livro a dois assuntos importantes: o costume de usar faixas nos bebês e o banho. Totalmente contrário às faixas, chamava-as de "Gólgota de panos" comentando que não havia razão para o uso desta peça tão popular dos enxovais de bebês até muito recentemente. O banho merece uma atenção mais detalhada do autor, pois criticava as crendices a respeito da água do banho e as práticas populares de acrescentar ervas, cachaça ou gema de ovo. Para as mães que faziam do primeiro banho 'um cavalo de batalha', Prado as apaziguava com os doze mandamentos do banho, examinando o tipo de banheira, a quantidade de água, a temperatura, o jeito de segurar a criança, a seqüencia das partes do corpo a serem lavadas, o tipo de sabonete, a toalha aquecida, o uso de talco e da vaselina e, por fim, o cuidado com o coto umbilical.

Grande parte dos ensinamentos e reprovações de Prado refere-se à alimentação da criança. Novamente as mesmas críticas às práticas e às terapias leigas e o primado da disciplina na alimentação. Defensor da amamentação materna, Prado ensina às mães que não basta dar $o$ seio ao bebê, mas é necessário saber como fazê-lo e com que regularidade. A palavra-chave das lições sobre a amamentação e a alimentação diferenciada é regularidade. A mãe devia amamentar o recém-nascido a cada três horas, nem mais, nem menos, não cedendo aos choros, como já explicado nas primeiras lições do livro. Com o crescimento da criança a alimentação passava a ser mais variada e Prado ensina que na técnica alimentar "a questão do número é de importância capital", ou seja, a quantidade era tão importante quanto a qualidade dos alimentos e o horário das refeições. Decorrem dessa técnica disciplinar da alimentação os dois instrumentos mais importantes que uma mãe devia ter para seguir um regime alimentar ideal: o relógio e a balança. "O relógio servirá para metodizar as mamadeiras de 3 em 3 horas, enquanto a balança, por meio das pesagens freqüentes, dirá a última palavra sobre o progresso nutritivo do seu filhinho" (Prado, 1938, p.264).

A pedagogia de Prado se fundamenta, portanto, no afastamento das pessoas leigas para que a mãe apenas recorresse aos ensinamentos da puericultura pela consulta ao pediatra ou, na falta dele, pela leitura do seu livro. Também é de fundamental importância que a mãe siga corretamente e sem desvio de atenção o método da disciplina, não cedendo aos desejos da criança e nem dando ouvidos aos conselhos de vizinhas e avós. Nesse sentido, a disciplina preconizada pelo método de Prado não visava somente à criação dos filhos, como anunciava o título do seu livro, mas das próprias mães, pois sem a mudança do comportamento delas e de seus valores com a aceitação dos princípios da puericultura, não seria possível, como sabiam os médicos, o processo de aculturação das práticas de cuidados infantis, nem a popularização do saber médico. Para criar filhos era necessário criar novas mães: essa é a principal lição do livro de Carlos Prado.

Na mesma época em que Prado encetava armas contra as mulheres 'sabichonas', seu colega de especialidade, José Martinho da Rocha, lançava um livro escrito para as mães no Rio de Janeiro. Como mestre, ele se dirigia às suas caras leitoras por meio de um livro cujo título era Cartilha às mães, ou seja, estabelecia a princípio que a educação das mães era algo urgente e necessário, cabendo aos pediatras o papel de mestres educadores dos princípios da puericultura. 
Diferentemente de seu colega paulista, Martinho da Rocha procurava estabelecer uma relação de confiança com suas leitoras, sem recorrer ao tom severo de Prado, o qual explicava na apresentação de seu livro que este já se encontrava na oitava edição, alcançando uma tiragem de quarenta mil exemplares, o que demonstrava, segundo o autor, que as mães brasileiras procuravam criar bem os seus filhos, seguindo "os preceitos da boa técnica, fugindo sempre das noções tradicionais, sempre cheias de erros e abusões" (Prado, 1938, p.2). Portanto, livros como a sua cartilha não eram simplesmente uma imposição dos médicos pediatras, mas uma resposta à demanda das mães brasileiras que não queriam errar em assuntos tão importantes como a saúde dos filhos.

Também no formato a Cartilha às mães diferia do livro de Prado. Ela se dividia em sessenta capítulos curtos, escritos numa linguagem acessível e ilustrados com desenhos de J. Carlos, um ilustrador e chargista bastante conhecido no meio jornalístico e editorial do Rio de Janeiro dos anos 20 e 30. Além de ser mais acessível, a linguagem é também mais afável. Ao falar dos bebês, Martinho da Rocha chama-os de pimpolhos ou guris; não é severo com as mães, mesmo quando reprova suas teimosias, agindo como um mestre na maior parte das vezes, aconselhando ao invés de ordenar, procurando guiar suas discípulas com tato, mas sem descuidar da sua autoridade.

Essa é uma questão com a qual todos os médicos pediatras concordavam, e Martinho da Rocha não destoa de seus colegas no que diz respeito à autoridade do pediatra e do saber puericultor. A primeira lição que as mães deviam aprender era fugir dos leigos, em especial das leigas, da mesma forma que as leitoras de Prado haviam aprendido. Martinho da Rocha explicava às mães que diante de qualquer dúvida elas deviam procurar o médico pediatra; não qualquer médico, mas somente o especialista em crianças.

O método explicado por Martinho da Rocha é também fundamentado na disciplina e na regularidade. Embora as instruções relacionadas à amamentação materna tenham a mesma regularidade de intervalo, respeitando-se três horas, Martinho da Rocha é mais específico e orienta que a criança deve mamar vinte minutos em cada seio. A disciplina com os horários não se justificava só pelo aspecto nutricional, mas porque a criança devia aprender a se submeter à disciplina estabelecida pelos adultos, no caso a mãe, afinal, como explicava o autor às suas leitoras, "é de pequenino que se torce o pepino" (Rocha, s.d., p.24).

Quanto ao comportamento da criança Martinho da Rocha seguia as mesmas orientações de seus colegas: silêncio, evitar passeios no colo, balanços, cantigas, cócegas e beijos. Contrário a qualquer forma de excitação, Rocha preferia que as crianças só fossem para o colo quando estritamente necessário, ou seja, para amamentar ao seio, tomar banho, trocar de roupa ou sair de casa. Mesmo quando a criança passava a ser alimentada, ela devia ficar no berço, com a mãe segurando a mamadeira e não o bebê. A disciplina, explicava Martinho da Rocha, não era só para educar o bebê, mas a própria mãe, pois tudo que se relacionava à criança, da amamentação à confecção de roupinhas, devia ser controlado e executado por ela, o que exigia, nas palavras do autor, "paciência, disciplina, perseverança e altruísmo" (Rocha, s.d., p.24).

A preocupação com a qualidade da alimentação das crianças era comum aos médicos pediatras, pois as doenças gastrointestinais eram as principais responsáveis pelas altas taxas de mortalidade infantil. Martinho da Rocha é muito minucioso com a dieta dos bebês, aconselhando as mães a tomarem todos os cuidados na preparação da alimentação, munindose de utensílios diversos e graduados, "tudo em gramas e centímetros cúbicos" (Rocha, s.d.). 
Qualquer mudança, por menor que fosse, na alimentação do bebê, devia ser orientada e recomendada somente pelo médico, devendo a mãe comportar-se como uma enfermeira, que não pode tomar decisões de ordem terapêutica sozinha.

Martinho da Rocha defendia que as escolas deviam incluir nos seus currículos noções de culinária e os ensinamentos da higiene infantil para que as futuras mães fossem orientadas desde cedo na puericultura: "seria vantajoso que as noivas fizessem estágio numa maternidade ou numa creche antes do casamento" (Rocha, s.d., p.131). Da mesma forma, recomendava a aprendizagem dos elementos da pedagogia moderna, pois em seu livro trata do comportamento infantil, abordando assuntos como castigos corporais - só admitidos em algumas situações -, as teimosias infantis, os tipos de brinquedos e a conveniência dos jardins de infância, defendidos pelo autor. O resultado de uma educação infantil baseada nos princípios da puericultura e conduzida diligentemente pela mãe informada e também educada só poderia ser positivo: "com ordem e método na vida, aliados à disciplina, resultante da freqüência ao jardim de infância, ao lado da regularidade alimentar e funções psíquicas guiadas convenientemente (dosagem de excitação intelectual), muito lucrarão o físico e a inteligência" (Rocha, s.d., p.224-225).

Para tanto, o papel da mãe era fundamental. Martinho da Rocha não estava satisfeito com o nível de educação das mães brasileiras que, segundo ele, eram muito amorosas com seus filhos, mas despreparadas, desinformadas e inexperientes. Seu livro procurava sanar as falhas dessa educação para a maternidade. Nesse sentido, seu método pedagógico visava transformar as mães em enfermeiras, e a primeira lição que uma mãe-enfermeira devia aprender era observar e relatar os fatos ao médico, sem tomar iniciativa: "boa enfermeira é a mãe que narra honestamente o que viu, sem fantasias, sem interpretações ... Há, entretanto, mães nervosas que nunca são boas enfermeiras, em vez de observarem calmamente o petiz, irritam o médico com intervenções desastrosas, com insinuações impertinentes, quando não o culpam por acidentes naturais da moléstia, falta-lhes calma, poder natural de observação, visão prática das coisas, educação à obediência passiva das prescrições" (Rocha, s.d., p.132).

O livro ensina com detalhes e minúcias como preparar mamadeiras, mingaus, mucilagens, 'papinhas', caldos, sucos e outras refeições à base de frutas, legumes e carnes. Fornece também receitas, especialmente das mamadeiras feitas com leite em pó, uma qualidade de leite disponível no mercado brasileiro desde a década de 1920, como Lactogeno, Nestogeno, Glaxo e Pelargon. A 'mamãe moderna' era bem informada e bem equipada com os utensílios domésticos, como a balança, o termômetro e o indispensável relógio. Entretanto, o mais importante era que ela se encarregasse da alimentação dofilho, como do banho, das roupas e dos primeiros socorros, como boa enfermeira que devia ser, não atribuindo a ninguém a responsabilidade pela criação do seu filho, nem compartilhando a maternidade com avós, criadas ou qualquer outra pessoa.

Cartilha às mães não difere muito do livro de Prado, nem mesmo dos famosos manuais de puericultura em voga no exterior. O médico estava em primeiro plano, a mãe era entendida como a aprendiz obediente e passiva, e o método rigoroso pretendia disciplinar a criança e a mãe. A cartilha enfatiza o papel da mãe, reproduzindo uma relação assimétrica profissional entre médicos e enfermeiras. Percebe-se o quanto Martinho desejava formar mães por meio de uma cartilha que ensinasse não só as técnicas diversas, os nomes científicos das vitaminas, as últimas novidades da pedagogia sobre o comportamento infantil e a identificação dos sintomas das doenças infantis, mas principalmente o reconhecimento do poder do pediatra. A cartilha 
é direcionada às mães, mas a personagem principal é o pediatra, o único capaz de estabelecer a verdade e corrigir os erros das mães, conforme fica bastante claro nesta advertência: "Escolhido o médico do seu filho, escutem com pertinácia suas ordens; não se moldem às objeções de vizinhas bem intencionadas ... Nada façam por iniciativa própria, ou alvitre de 'entendidas'" (Rocha, s.d., p.6-7).

Em 1941 foi publicado o mais famoso manual de puericultura do Brasil, tornando-se, a partir de então, um campeão de vendas desse tipo de publicação. Trata-se do livro $A$ vida do bebê, de Rinaldo de Lamare, pediatra nacionalmente conhecido e famoso que faleceu em 2002. Mulheres de classe média que foram mães a partir da década de 1950 dificilmente deixaram de ler $A$ vida do bebê, pois além de abordar os assuntos mais tradicionais da puericultura e da pediatria, esse livro foi inovador ao divulgar conhecimentos da psicologia (a teoria das fases do desenvolvimento) e discutir temas como filho único, adoção e filhos de pais desquitados. Mas certamente seu sucesso se deve também ao estilo, mais amigável e menos autoritário, e a uma insistência menor na autoridade médica, embora esta fosse reconhecível desde as primeiras páginas do livro.

O livro de Rinaldo de Lamare pode ser considerado como de transição entre os manuais mais rígidos e severos da disciplina alimentar e do controle das emoções, tratados anteriormente. Certamente De Lamare prega a disciplina e a regularidade, sendo também contrário às carícias, balanços e cantigas, mas defende uma educação mais liberal na qual o pai e não só a mãe tem papel importante, tanto no estabelecimento de regras e normas, quanto na participação em brincadeiras e jogos. ${ }^{4}$

A linguagem é direta, mais simples que a de seus colegas aqui analisados, não fazendo recriminações nem dando ordens, mas sim conselhos e orientações. Na realidade, o roteiro é o mesmo dos outros livros, ou seja, banhos, vestuário, amamentação, alimentação artificial e doenças infantis, mas inclui outros temas, como a formação da personalidade, a televisão e sua influência na educação das crianças (De Lamare, 1963) e 'bebês-problema', além daqueles comentados anteriormente. Outro elemento diferenciador nesse livro é o fato de que Rinaldo De Lamare faz propaganda de produtos de higiene infantil, recomendando o uso dos produtos Johnson \& Johnson, bastante divulgados também na imprensa, especialmente nas revistas.

Apesar do tom amigável, não há dúvidas quanto à autoridade do pediatra. Contudo, essa autoridade é dividida com os pais. As outras pessoas e seus conselhos não profissionais são criticados por De Lamare, mas sem usar de linguagem agressiva para com elas, nem insistir sobre o tema. Não se vê nesse livro referências às 'sabichonas' nem aos 'entendidos' que tanto Prado quanto Martinho da Rocha execravam. Talvez isso se explique pelo fato de que na época em que o livro de De Lamare foi escrito e as outras edições foram produzidas - décadas de 1940, 1950 e 1960 - a autoridade dos pediatras estivesse mais consolidada e reconhecida, não só pelas famílias e as mães, mas também pelo Estado, com a criação do Departamento Nacional da Criança e a implementação de políticas de saúde e de assistência materno-infantil, com médicos pediatras em postos de decisão, de execução e fiscalização.

Outro aspecto diferencial nesse livro é a presença do pai. Se até então os livros ignoravam a presença paterna e seu papel na criação dos filhos, De Lamare é o primeiro a mencionar sua importância: "o pai moderno colabora, orgulhoso, na criação do seu filho. Muda fraldas, prepara mamadeiras, empurra o carrinho enquanto a mãe cuida dos afazeres domésticos" (De 
Lamare, 1963, p.11). Embora a ênfase continue na díade mãe-filho, há várias passagens nas quais o autor se refere aos pais, bem como à sua autoridade e à harmonia que deve existir no lar para que a educação produza bons frutos. Seu modelo de família é a mãe devotada aos filhos e consciente de suas responsabilidades, enquanto o pai deve ser o provedor para evitar que sua esposa tenha de se ausentar do lar, contribuindo com ela nos cuidados dos filhos e na educação baseada no exemplo moral, na autoridade e no carinho.

De Lamare também defende a educação das mães antes mesmo que elas se casem e constituam família, pois a formação de uma jovem mulher não estaria completa sem um curso de puericultura, tão importante quanto a primeira comunhão e o diploma de colação de grau. Da mesma forma que Martinho da Rocha, De Lamare era adepto de uma pedagogia materna essencialmente prática que formasse mães-enfermeiras. Nesse sentido, o método não diferia muito do de seus colegas, mas De Lamare é mais paciente com as mães, ensinando-as não só a agir com regularidade e disciplina, mas explicando com detalhes o que então os médicos pediatras ordenavam, como se as mulheres soubessem determinadas coisas por instinto, como por exemplo, a amamentação natural.

Os puericultores, pediatras e obstetras, de uma forma geral, defendiam ardorosamente a amamentação natural, recriminando duramente as mães que não davam o próprio leite aos seus filhos. A condenação era assentada em argumentos fisiológicos, mas acima de tudo morais. De Lamare não só determinava os horários - mamadas a cada três horas -, mas a técnica para sentar, para segurar o bebê, para preparar o seio e dá-lo ao bebê e os cuidados com o seio para evitar rachaduras, e explicava os tipos de bebês conforme o modo como mamavam: robusto, nervoso, indiferente, guloso e folgado. Quanto à qualidade do leite materno e à falta de leite, De Lamare explicava às mães que não havia leite fraco e que a ausência do leite só podia ser diagnosticada pelo médico. Embora o assunto fosse da maior importância De Lamare não ameaçava as mães, pelo contrário, lembrava que tudo era muito simples e que a mãe devia agir sempre com naturalidade: "Nada de aflições" (De Lamare, 1963, p.33).

De Lamare escreve pensando na mãe ideal e esta é das classes favorecidas, pois não trabalha fora de casa e está disponível o tempo todo para o filho. A mãe, especialmente quando amamentava, devia ser poupada de qualquer tipo de dissabor para evitar a interrupção do aleitamento. O marido devia evitar a todo custo discutir e mesmo brigar com a esposa enquanto ela amamentava, e a mãe tinha de se submeter a uma dieta saudável, evitando as canjicas e a cerveja preta, que só serviam para engordar e não aumentavam a quantidade de leite. Além da dieta, seu estilo de vida devia ser regrado evitando emoções fortes: "a nutriz deve ter o melhor e mais agradável possível método de vida. Passeios, exercícios sem exagero, diversões simples, tranqüilidade de espírito (se as empregadas o permitirem), devem repousar no mínimo 10 horas por dia, 8 durante a noite e 2 durante o dia." (De Lamare, 1963, p.35). Certamente esse estilo de vida era possível para poucas mulheres.

Seu modelo de mãe é a mulher educada, bem informada, permeável às novas regras da puericultura e obediente ao pediatra do seu filho. De Lamare não enfatizava sua autoridade como seus colegas faziam, embora em algumas passagens do livro lembrasse às leitoras que, como boas mães-enfermeiras, não deviam tomar nenhuma decisão sem antes consultar o pediatra, pois somente ele podia considerar com isenção e conhecimento científico as condições de saúde da criança. As mães-enfermeiras deviam ser boas observadoras, registrar tudo com 
detalhes, de preferência num caderno de anotações, e na consulta dirimir qualquer dúvida.

De Lamare representa um novo modelo de pediatra. Enquanto Prado e Martinho da Rocha ainda precisavam afirmar a sua autoridade em meio a outros concorrentes da medicina popular, De Lamare pouca atenção dava para essa concorrência, pois já escrevia para mulheres que começavam a mudar seus hábitos, a começar pelo tipo de parto. A partir das décadas de 1930 e 1940 passou-se a utilizar as maternidades, embora o parto domiciliar fosse ainda predominante. Além de ter ocorrido aumento na quantidade de partos hospitalares, as mães começavam a levar os filhos com maior freqüência aos consultórios dos pediatras, pois nesse período a propaganda do governo em favor da saúde infantil encontrou grande apoio na divulgação de suas campanhas e dos preceitos da puericultura nos jornais e revistas, isso sem falar dos concursos de robustez infantil que certamente estimulavam as mães para a competição, além de serem um meio bastante eficaz de propaganda da puericultura e dos produtos da indústria de alimentos e de higiene.

O livro A vida do bebê encerra uma fase da pedagogia materna e inicia outra, na qual a ênfase sobre a criança é cada vez maior, introduzindo os conhecimentos da psicologia e a questão comportamental. Se no começo do século XX o grande mal era a mortalidade infantil devido a doenças relacionadas à nutrição e às condições de higiene, a partir da década de 1960 os livros e as revistas com suas seções escritas pelos especialistas passam a dar cada vez mais importância às relações afetivas entre mães e filhos. 'Mães ausentes' ou 'mães superprotetoras' podiam colocar em risco a saúde mental e o equilíbrio psíquico de seus filhos, gerando ansiedade e culpa, principalmente para as mulheres que trabalhavam e desejavam ter uma vida profissional (Ehrenreich, English, 2003, p.244-254).

O que esses dois modelos de educação das mães têm em comum? Não se pode negar que em alguns aspectos a qualidade da vida das crianças melhorou, principalmente no aspecto da alimentação, da prevenção e da cura de doenças infectocontagiosas que há um século dizimavam crianças de todas as classes sociais. Mas se voltarmos a atenção para as mães a maternidade se tornou uma experiência normalizada que passou a exigir dedicação exclusiva e um acúmulo de responsabilidade pelo bem-estar da criança. A pedagogia materna que se consolidou no século XX contribuiu muito para a ansiedade e a insegurança feminina em relação à maternidade ao produzir o mito da mãe perfeita, além da solidão, pois se aparentemente a mãe podia contar com o pediatra e depois com outros especialistas para orientá-la, na realidade a pedagogia materna as isolou na díade mãe-filho. Foi para consolidar esse laço - naturalizado e romantizado - que os médicos obstetras e pediatras tanto escreveram e militaram procurando transformar as mulheres em mães devotadas, discípulas obedientes e leitoras agradecidas.

\section{NOTAS}

* Este artigo é resultado de parte da pesquisa de pós-doutorado desenvolvida junto à Casa de Oswaldo Cruz/Fiocruz, financiada pelo CNPq e pela Fundação Araucária - Paraná.

${ }^{1}$ Ver http://www.iin.oea.org. Em 1927 foi criado no Uruguai o Instituto Interamericano da Criança.

${ }^{2}$ A Associação Americana de Economia Doméstica foi fundada em 1909 (Ehrenreich, English, 2003, p.180). 
${ }^{3}$ São exemplares dessa literatura: Franco, 1790; Gusmão, 1685.

${ }^{4}$ É importante lembrar que a edição que analiso é de 1963, portanto há que se considerar a influência das idéias permissivas do especialista norte-americano Benjamin Spock, bem como da psicologia do desenvolvimento. Os médicos e psicólogos passam a se dirigir às mães de forma mais amigável, são menos rígidos nas prescrições e mais compreensíveis perante as inseguranças maternas.

\section{REFERÊNCIAS BIBLIOGRÁFICAS}

AGUIAR, Álvaro; MARTINS, Reinaldo Menezes (Ed.)

História da pediatria brasileira: coletânea de textos e depoimentos. Rio de Janeiro: Sociedade Brasileira de Pediatria; Nestlé. 1996

BOCK, Gisela; Thane, Pat (Ed.)

Maternidad y políticas de género. Madrid: Cátedra. 1996

COSTA, Clovis Corrêa da

Puericultura. Rio de Janeiro: Departamento

Nacional da Criança/Ministério da Saúde. 1955

COSTA, Jurandir Freire

Ordem médica e norma familiar. Rio de Janeiro: Graal. 1979

DE LAMARE, Rinaldo

A vida do bebê. Rio de Janeiro: Borsoi. 1.ed., 1941. 1963

DEL PRIORE, Mary

Ao sul do corpo: condição feminina

maternidades e mentalidades no Brasil Colônia. Rio de janeiro: J. Olympio; Brasília: Ed. UnB. 1993

EHRENREICH, Bárbara; ENGLISH, Deirdre Para seu próprio bem: 150 anos de conselhos de especialistas para as mulheres. Rio de Janeiro: Rosa dos Tempos. 2003

FORNA, Aminatta

Mãe de todos os mitos: como a sociedade modela e reprime as mães. Rio de Janeiro: Ediouro. 1999

FRANCO, Francisco de Melo

Tratado de educação física dos meninos para uso da nação portuguesa. Lisboa: Academia Real de

Ciências. 1790
GUSMÃO, Alexandre de

A arte de criar bem os filhos na idade de puerícia. Lisboa: Miguel Deslandes. 1685

HULBERT, Ann

Raising America: experts, parents and a century of advice about children. New York: Vintage

Books. 2004

MARTINS, Ana Paula V.

Visões do feminino: a medicina da mulher nos séculos XIX e XX. Rio de Janeiro: Ed. Fiocruz. 2004

PRADO, Carlos

Vamos criar seu filho!. São Paulo: Guairá. 1938

PRIMEIRO CONGRESSO...

Primeiro Congresso Brasileiro de Proteção à

Infância. Rio de Janeiro: Empresa Graphica Editora. 1925

ROCHA, José Martinho da

Cartilha das mães. Em elaboração com Odilon de Andrade Filho. 8.ed. Rio de Janeiro: Civilização Brasileira. s.d.

SETA, Marismary Horsth de

Instituto Fernandes Figueira: delineamento de 50 anos de história institucional. (1924-1974).

Dissertação (Mestrado) - Instituto de Medicina Social / Universidade Estadual do Rio de Janeiro, Rio de Janeiro. 1997

\section{THEBAUD, Françoise}

Quand nos grand-mères donnaient la vie: la maternité em France dans l'entre-deux-guerres. Lyon: Presses Universitaires de Lyon. 1986 